\title{
What is the Role of the Neutrophil: Lymphocyte Ratio in Colorectal Cancer?
}

\author{
Kolorektal Kanserde Nötrofil:Lenfosit Oranının Rolü Nedir?
}

\author{
(1) Debamita Bhattacharjee, (1) Philip Quirke \\ University of Leeds School of Medicine, Leeds Institute of Medical Research, Pathology and Data Analytics, Leeds, United Kingdom
}

\begin{abstract}
IIIIIIII| ABSTRACT
The composition and cell-to-cell interactions of the peripheral immune compartment are known to influence outcomes in multiple disease entities, both neoplastic and otherwise. There is an ongoing search for a reliable biomarker in the peripheral immune compartment that can predict outcomes in colorectal cancer, given its high mortality rates. The neutrophil:lymphocyte ratio (NLR) has been suggested as one such marker, given its accessibility. This review discusses the current evidence behind the use of the NLR in predicting different aspects of colorectal cancer (CRC) behaviour, from survival to recurrence, metastasis, tumour biology, response to therapy and CRC complications. We also discuss the debate in the literature surrounding the use of other peripheral immune compartment biomarkers compared with the NLR for this purpose and ideas for future research.
\end{abstract}

Keywords: Colorectal cancer, neutrophil: lymphocyte ratio, survival

\section{|IIIIIII|| ÖZ}

Periferal immün kompartmanının kompozisyonunun ve hücreler arası etkileşimlerinin, hem neoplastik hem de neoplastik olmayan birçok hastalıkta sonlanımı etkilediği bilinmektedir. Periferik bağışıklık kompartmanında, yüksek mortalite oranı olan kolorektal kanserdeki sonlanımı tahmin edebilen güvenilir bir biyobelirteç için devam eden bir arayış vardır. Nötrofil:lenfosit oranının (NLO) kolay erişilebilirliği göz önüne alındığında, böyle bir belirteç olabileceği öne sürülmüştür. Bu derleme, sağkalım, nüks, metastaz, tümör biyolojisi, tedaviye yanıt ve komplikasyonlar gibi kolorektal kanser davranışının farklı yönlerini tahmin etmede NLO kullanımının arkasındaki mevcut kanıtları tartışmaktadır. Literatürdeki veriler ışığında, NLO'ya kıyasla diğer periferik immün kompartman biyobelirteçlerinin bu amaçla kullanımı tartışlacak ve gelecekteki araştırmalar için fikirler üzerinde durulacaktır.

Anahtar Kelimeler: Kolorektal kanser, nötrofil: lenfosit oranı, sağkalım

\section{Introduction}

Colorectal cancer $(\mathrm{CRC})$ is the world's third most common cancer and the fourth most common cause of cancer mortality. Blood-based biomarkers are attractive for the management of this disease, given their ease of access and amenability to repetitive sampling. Low-grade, chronic inflammation has long been associated with a range of diseases and poor outcomes. Many different markers of inflammation have been described over the years; however, apart from the erythrocyte sedimentation rate and plasma viscosity, these are not used in routine clinical assessment. One simple marker that has been widely described, the neutrophil:lymphocyte ratio (NLR), has been generally overlooked in clinical practice. The aim of this review is to discuss its role as a biomarker in CRC, compare its value against other biomarkers and encourage its wider adoption into mainstream clinical practice.

\section{What is the Neutrophil:Lymphocyte Ratio (NLR)?}

The NLR is an inexpensive, readily available marker, which is proposed to provide additional risk stratification beyond other more traditional risk scores. Calculation of the NLR simply involves dividing the peripheral blood neutrophil count by the lymphocyte count on a full blood count. The NLR has been suggested as a good marker of systemic lowgrade inflammation, ${ }^{1}$ which is associated with a poorer outcome in many disease types.

Address for Correspondence/Yazışma Adresi: Debamita Bhattacharjee, MD, 


\section{The role of the NLR in Colorectal Cancer (CRC)}

The concept of the influence of the NLR in CRC is not new. Back in 2005, a landmark study by Walsh et al. ${ }^{2}$ identified that a NLR $>5$ (i.e. neutrophils present at 5 times the number of lymphocytes) was correlated with poor overall and cancer-specific survival in univariate analyses. Other studies have set a lower value of 2 or 3 to dichotomise populations, thus increasing the number of individuals in the poorer prognosis group.

This observation has since been replicated by subsequent studies (Table 1) and supported by pooled analysis of a meta-analysis. ${ }^{3}$ With respect to single studies, there are many examples where this effect of NLR on CRC survival outcomes has been replicated. In patients undergoing elective resection of colorectal cancer, a lower postoperative NLR was found to correlate with longer cancer-specific and disease-free survival. ${ }^{4}$ Similarly, another study ${ }^{5}$ found that a high preoperative NLR $(>3)$ in colon cancer patients was associated with worse disease-free survival and cancerspecific death [heart ratio (HR) 1,377 95\% confidence interval (CI) $1,104-1,717, \mathrm{p}=0.014]$. It is of note that this difference was larger in colon cancer than in rectal cancer patients. Consistently, another study investigating patients with early-stage colorectal cancer ${ }^{6}$ who were candidates for curative surgery found that there was a statistically significantly poorer outcome in 5-year disease-free survival and cancer-specific survival in those with a high NLR compared with those with a low NLR. Following a similar pattern of findings, a study looking at stage II colon cancer ${ }^{7}$ found that an elevated NLR was an independent predictor of poorer overall survival but not disease-free survival when analysed using Cox regression analysis. A study conducted at our institute ${ }^{8}$ found that the NLR predicted disease-free and overall survival in our patients with primary colorectal malignancy.

To summarise an overview of the literature, a systematic review $^{9}$ identified higher 3-year and 5-year survival rates in patients with a low NLR compared with those with a high NLR ( $77.8 \%$ vs $61.8 \%$ ), and the range of cut-off values used to define the high- and low-NLR groups varied from 2 to 5 .

\section{NLR in Metastatic Colorectal Cancer}

Liver metastases develop in up to $40 \%$ of patients with a high recurrence rate, even after primary bowel resection. The NLR is suggested to be one such marker in multiple studies (Tables 2, 3).

A systematic review ${ }^{9}$ identified multiple studies reporting survival results in patients with CRC and liver metastases. Similar to the pattern observed in non-metastatic disease, the low-NLR group had a better 3-year survival rate compared with the high NLR group ( $64.74 \%$ vs $45.1 \%$ respectively). This systematic review identified multiple studies showing a differential 5-year survival rate in this patient group, the 5-year survival being higher in patients with a low NLR than in those with a high NLR ( $47.6 \%$ vs $27 \%$, respectively). A further meta-analysis, including 1,685 patients, found that an elevated pre-treatment NLR was associated with poor overall and recurrence-free survival in patients with colorectal liver metastasis. ${ }^{10}$ A significant negative finding of the study was that there was no correlation between NLR and the timing and number of metastases at the time of diagnosis.

Using a cut-off value of 5, Halazun et al. ${ }^{11}$ found that an increased NLR decreased the 5-year survival rate and risk of recurrence in patients who underwent resection for colorectal liver metastases. Neal et al. ${ }^{12}$ found that in a multivariable analysis, a high NLR was independently associated with major infectious complications after hepatectomy, which may be an explanation for the worse survival rates in this patient group observed in previous studies.

A prospective, multicentre randomised Italian Trial in Advanced Colorectal Cancer ${ }^{13}$ randomised patients to receive first-line chemotherapy with or without bevacizumab (an anti-angiogenic monoclonal antibody) and found that NLR was a marker of progression-free survival and overall survival in patients with metastatic colorectal cancer. Moreover, those with a high NLR treated with bevacizumab and chemotherapy had a worse overall survival than those treated with chemotherapy alone, although the pathophysiological explanation for this was unclear.

\section{NLR and the Tumour Recurrence Rate}

CRC can recur locally at multiple sites, including intra-abdominal lymph nodes, the peritoneum and the retroperitoneum or anastomosis. Higher NLR values are associated with a higher tumour recurrence rate in patients with stage II and stage III disease. ${ }^{9}$ A study based in Leeds ${ }^{8}$ found that a NLR $>/=5$ was correlated with greater disease recurrence. The above finding was in agreement with a previously published paper ${ }^{14}$, which found that a NLR $>5$ was a significant and independent factor predictive of recurrent colorectal cancer, when all stages of CRC were included. In a study population of patients with stage IIA colon cancer undergoing curative resection, an elevated NLR was found to be an independent predictor of worse recurrence-free survival $^{7}$, with a 5 -year recurrence-free survival of $91.4 \%$ in those with a normal NLR and $63.8 \%$ for those with an elevated NLR.

\section{NLR and Tumour Biology}

A systematic review identified multiple studies showing that poorly differentiated tumours were more likely to be correlated with higher NLR values ${ }^{9}$ This same systematic review also identified multiple studies which showed a significant correlation between a high NLR and an advanced tumour stage. 
Table 1. A summary of the literature discussing NLR and survival in patients with non-metastatic colorectal cancer

\begin{tabular}{|c|c|c|c|c|c|}
\hline Author & Title & Source & Sample size & NLR cut off & Findings \\
\hline Li et al. ${ }^{3}$ & $\begin{array}{l}\text { Prognostic } \\
\text { significance of } \\
\text { elevated preoperative } \\
\text { neutrophil-to- } \\
\text { lymphocyte ratio for } \\
\text { patients with colorectal } \\
\text { cancer undergoing } \\
\text { curative surgery: A } \\
\text { meta-analysis }\end{array}$ & $\begin{array}{l}\text { Medicine } \\
\text { (Baltimore) }\end{array}$ & 5897 & $2.3-5$ & $\begin{array}{l}\text { An elevated NLR correlates with } \\
\text { lower overall survival, disease- } \\
\text { free survival, recurrence-free } \\
\text { survival and disease-specific } \\
\text { survival after treatment. }\end{array}$ \\
\hline
\end{tabular}

Impact of the perioperative neutrophil-to-

Kubo et al. ${ }^{4}$ lymphocyte ratio on the long-term survival following an elective resection of colorectal carcinoma

International

Journal of

Colorectal

Disease

NLR value was calculated prior to curative resection, on the first postoperative day and the third or fourth postoperative day: Patients with low median NLR value at all time points were given a score of 0 , whereas those with a high median NLR at all time points were assigned a score of 3 . Following the above scoring, those with a score of 0 or 1 were classed as the low perioperative NLR group, whereas the high perioperative NLR group had scores of 2 or 3 .

The cut-off value for low and high NLR levels are as follows:

Median NLR pre-op 2.29

Median NLR postoperative day 1 : 7.90

Median NLR: Postoperative day 3: $5.10_{-}$

Can neutrophil-tolymphocyte ratio predict the survival

Chiang et al. ${ }^{5}$ of colorectal cancer patients who have received curative surgery electively?

International

Journal of

Colorectal

3857

3

Disease

Preoperative neutrophil-to-

Shin et al. ${ }^{6}$ lymphocyte ratio predicts survival in patients with T1-2N0 colorectal cancer

Effect of preoperative neutrophil-lymphocyte ratio on the surgical

Hung et al. ${ }^{7}$ outcomes of stage II colon cancer patients who do not receive adjuvant chemotherapy

International

Journal of

Colorectal

1040

5

Disease
A high perioperative NLR is an independent risk factor for both cancer-specific and disease-free survival.
A NLR $>3$ was associated with worse 5 year disease-free survival, with a larger difference in colonic vs rectal cancer. An elevated NLR was also associated with clinicopathological factors related to advanced diseases.

Preoperative NLR is a prognostic factor for disease-free survival and cancer-specific survival in stage I colorectal cancer patients.

Cox regression analysis revealed that an elevated NLR is an independent predictor of overall survival but not disease-free survival.
Systemic neutrophilto-lymphocyte ratio in colorectal cancer: the

Pine et al. ${ }^{8}$ relationship to patient survival, tumour biology and local lymphocytic response to tumour

\section{British}

Journal of

Cancer
An elevated NLR predicts disease-free and overall survival and more advanced tumour biology. The NLR is not associated with tumour mutation status.

NLR: Neutrophil:lymphocyte ratio 
Table 2. A summary of the literature discussing NLR and prognosis in metastatic colorectal cancer patients

\begin{tabular}{|c|c|c|c|c|c|}
\hline Author & Title & Source & Sample size & NLR cut off & Findings \\
\hline Haram et al. ${ }^{9}$ & $\begin{array}{l}\text { The prognostic value of } \\
\text { neutrophil-to-lymphocyte ratio } \\
\text { in colorectal cancer: A systematic } \\
\text { review }\end{array}$ & $\begin{array}{l}\text { Journal of Surgical } \\
\text { Oncology }\end{array}$ & 10,259 & 5 & $\begin{array}{l}\text { A NLR }>5 \text { is associated with } \\
\text { worse } 3 \text { - and } 5 \text {-year survival } \\
\text { in CRC patients with liver } \\
\text { metastases. }\end{array}$ \\
\hline Tang et al. ${ }^{10}$ & $\begin{array}{l}\text { Prognostic significance of } \\
\text { neutrophil-to-lymphocyte ratio } \\
\text { in colorectal liver }\end{array}$ & PLoS One & 1,685 & $2.5-5$ & $\begin{array}{l}\text { An elevated NLR is associated } \\
\text { with poor overall survival and } \\
\text { recurrence-free survival in } \\
\text { colorectal patients with liver } \\
\text { metastases. }\end{array}$ \\
\hline Halazun et al. ${ }^{11}$ & $\begin{array}{l}\text { Elevated preoperative } \\
\text { neutrophil-to-lymphocyte ratio } \\
\text { predicts survival following } \\
\text { hepatic resection for colorectal } \\
\text { liver metastases }\end{array}$ & $\begin{array}{l}\text { European Journal of } \\
\text { Surgical Oncology }\end{array}$ & 440 & 5 & $\begin{array}{l}\text { An elevated NLR is associated } \\
\text { with a worse } 5 \text {-year survival and } \\
\text { tumour recurrence. }\end{array}$ \\
\hline Neal et al. ${ }^{12}$ & $\begin{array}{l}\text { Preoperative systemic } \\
\text { inflammation and infectious } \\
\text { complications after resection of } \\
\text { colorectal liver metastases }\end{array}$ & Archives of Surgery & 202 & 5 & $\begin{array}{l}\text { A high NLR is associated } \\
\text { with postoperative infectious } \\
\text { morbidity and overall and } \\
\text { disease-free survival on } \\
\text { univariate analysis. }\end{array}$ \\
\hline Passardi et al. ${ }^{13}$ & $\begin{array}{l}\text { Inflammatory indexes as } \\
\text { predictors of prognosis and } \\
\text { bevacizumab efficacy in patients } \\
\text { with metastatic colorectal cancer }\end{array}$ & Oncotarget & 289 & 3 & $\begin{array}{l}\text { The correlation between lower } \\
\text { NLR levels and improved overall } \\
\text { and progression- free survival } \\
\text { was significantly associated with } \\
\text { the addition of bevacizumab to } \\
\text { first-line chemotherapy. }\end{array}$ \\
\hline
\end{tabular}

NLR: Neutrophil:lymphocyte ratio, CRC: Colorectal cancer

Table 3. A summary of the literature discussing the NLR and the response to oncological treatment

\begin{tabular}{|c|c|c|c|c|c|}
\hline Author & Title & Source & $\begin{array}{l}\text { Sample } \\
\text { size }\end{array}$ & $\begin{array}{l}\text { NLR cut } \\
\text { off }\end{array}$ & Findings \\
\hline Kaneko et al. ${ }^{21}$ & $\begin{array}{l}\text { Elevated Neutrophil-to- } \\
\text { Lymphocyte Ratio Predicts Poor } \\
\text { Prognosis in Advanced Colorectal } \\
\text { Cancer Patients Receiving } \\
\text { Oxaliplatin-Based Chemotherapy. }\end{array}$ & Oncology & 50 & 4.0 & $\begin{array}{l}\text { An elevated NLR is associated with overall } \\
\text { survival and the disease response rate in } \\
\text { patients with advanced or recurrent CRC } \\
\text { receiving oxaliplatin-based combination } \\
\text { chemotherapy. }\end{array}$ \\
\hline Kishi et al. ${ }^{23}$ & $\begin{array}{l}\text { Blood neutrophil-to-lymphocyte } \\
\text { ratio predicts survival in } \\
\text { patients with colorectal liver } \\
\text { metastases treated with systemic } \\
\text { chemotherapy. }\end{array}$ & $\begin{array}{l}\text { Annals of } \\
\text { Surgical } \\
\text { Oncology }\end{array}$ & 200 & 5 & $\begin{array}{l}\text { In patients with colorectal liver metastases } \\
\text { treated with chemotherapy and resection, } \\
\text { a NLR }>5 \text { was an independent predictor } \\
\text { of } 5 \text {-year survival. In this patient group, } \\
\text { preoperative chemotherapy normalised the } \\
\text { NLR and improved survival. } \\
\text { In the non-resection group receiving } \\
\text { chemotherapy only, an NLR }>5 \text { was an } \\
\text { independent predictor of worse } 3 \text {-year } \\
\text { survival. }\end{array}$ \\
\hline Botta et al. ${ }^{24}$ & $\begin{array}{l}1439 \text { POSTER Treatment- } \\
\text { related Changes in Systemic } \\
\text { Inflammatory Status, Measured } \\
\text { by Neutrophil-to-lymphocyte } \\
\text { Ratio, is Predictive of Outcome } \\
\text { in Metastatic Colorectal Cancer } \\
\text { Patients. }\end{array}$ & $\begin{array}{l}\text { European } \\
\text { Journal of } \\
\text { Cancer }\end{array}$ & 247 & 3 & $\begin{array}{l}\text { NLR }>3 \text { was a significant prognostic factor } \\
\text { for overall and progression-free survival in } \\
\text { patients with metastatic colorectal cancer } \\
\text { receiving first-line chemotherapy. } \\
\text { The reduction to a NLR }<3 \text { following } \\
\text { treatment was associated with a longer time } \\
\text { to event. }\end{array}$ \\
\hline
\end{tabular}


Table 3. continued

\begin{tabular}{|c|c|c|c|c|c|}
\hline Chua et al. ${ }^{25}$ & $\begin{array}{l}\text { Neutrophil/lymphocyte ratio } \\
\text { predicts chemotherapy outcomes } \\
\text { in patients with advanced } \\
\text { colorectal cancer. }\end{array}$ & $\begin{array}{l}\text { British Journal of } \\
\text { Cancer }\end{array}$ & 349 & 5 & $\begin{array}{l}\text { In patients with unresectable metastatic } \\
\text { colorectal cancer undergoing first- line } \\
\text { palliative chemotherapy, the NLR was } \\
\text { predictive of overall and progression-free } \\
\text { survival. Normalisation of NLR following } \\
\text { treatment could improve progression-free } \\
\text { survival. }\end{array}$ \\
\hline Turnbull et al. ${ }^{26}$ & $\begin{array}{l}\text { Chemotherapy to reverse } \\
\text { diminished immune responses } \\
\text { (IRs) associated with a raised } \\
\text { neutrophil-lymphocyte ratio } \\
\text { (NLR) in patients with advanced } \\
\text { colorectal cancer (aCRC). }\end{array}$ & $\begin{array}{l}\text { Journal of } \\
\text { Clinical } \\
\text { Oncology }\end{array}$ & 29 & 5 & $\begin{array}{l}\text { A high NLR is associated with reduced } \\
\text { overall survival and measured IRs in patients } \\
\text { with advanced colorectal cancer. The } \\
\text { NLR normalises after } 6 \text { weeks of first-line } \\
\text { chemotherapy, and their depressed IRs can } \\
\text { be reversed by chemotherapy. }\end{array}$ \\
\hline Wood et al. ${ }^{27}$ & $\begin{array}{l}\text { Derived neutrophil-to- } \\
\text { lymphocyte ratio as a prognostic } \\
\text { factor in patients with advanced } \\
\text { colorectal cancer according to } \\
\text { RAS and BRAF status: a post-hoc } \\
\text { analysis of the MRC COIN study. }\end{array}$ & $\begin{array}{l}\text { Anticancer } \\
\text { Drugs }\end{array}$ & 1603 & $\begin{array}{l}\text { dNLR } \\
\text { cut-off } \\
\text { was } 2.2\end{array}$ & $\begin{array}{l}\text { In patients with metastatic colorectal cancer, } \\
\text { a dNLR }<2.2 \text { was associated with better } \\
\text { overall survival in patients in all mutation } \\
\text { groups, but it did not predict the survival } \\
\text { benefit from the addition of cetuximab to } \\
\text { oxaliplatin. }\end{array}$ \\
\hline Chen et al. ${ }^{28}$ & $\begin{array}{l}\text { Cytokine profile and prognostic } \\
\text { significance of high neutrophil- } \\
\text { lymphocyte ratio in colorectal } \\
\text { cancer. }\end{array}$ & $\begin{array}{l}\text { British Journal of } \\
\text { Cancer }\end{array}$ & 1180 & 5 & $\begin{array}{l}\text { The NLR is a prognostic factor across } \\
\text { multiple settings of CRC, including } \\
\text { surgically resected stage II/III CRC, } \\
\text { metastatic colorectal cancer with liver } \\
\text { metastases after hepatectomy and previously } \\
\text { untreated and refractory metastatic CRC. } \\
\text { In a cohort of patients with colorectal } \\
\text { cancer, patients with liver metastases who } \\
\text { were refractory to standard treatments such } \\
5 \text { fluorouracil, NLR is not associated with } \\
\text { tumour mutation status. }\end{array}$ \\
\hline Shen et al. ${ }^{32}$ & $\begin{array}{l}\text { Baseline neutrophil-lymphocyte } \\
\text { ratio }(\geq 2.8) \text { as a prognostic factor } \\
\text { for patients with locally advanced } \\
\text { rectal cancer undergoing } \\
\text { neoadjuvant chemoradiation. }\end{array}$ & $\begin{array}{l}\text { Radiation } \\
\text { Oncology }\end{array}$ & 224 & 2.8 & $\begin{array}{l}\text { The baseline NLR can predict overall } \\
\text { survival in patients with locally advanced } \\
\text { rectal cancer undergoing neoadjuvant } \\
\text { chemoradiation, but it did not predict the } \\
\text { response to treatment. }\end{array}$ \\
\hline Hodek et al. ${ }^{33}$ & $\begin{array}{l}\text { Neoadjuvant chemoradiotherapy } \\
\text { of rectal carcinoma: Baseline } \\
\text { haematologic parameters } \\
\text { influencing outcomes. }\end{array}$ & $\begin{array}{l}\text { Strahlentherapie } \\
\text { und Onkologie }\end{array}$ & 173 & 2.8 & $\begin{array}{l}\text { NLR was a prognostic factor for overall } \\
\text { survival and primary tumour downstaging } \\
\text { (treatment response) in patients with } \\
\text { locally advanced rectal cancer treated with } \\
\text { neoadjuvant chemoradiotherapy. }\end{array}$ \\
\hline Carruther et al. ${ }^{34}$ & $\begin{array}{l}\text { Systemic inflammatory response } \\
\text { is a predictor of outcome in } \\
\text { patients undergoing preoperative } \\
\text { chemoradiation for locally } \\
\text { advanced rectal cancer. }\end{array}$ & $\begin{array}{l}\text { Colorectal } \\
\text { Disease }\end{array}$ & 115 & 5 & $\begin{array}{l}\text { An NLR }>/=5 \text { was associated with decreased } \\
\text { overall survival, time to local recurrence } \\
\text { and worse disease-free survival in patients } \\
\text { with locally advanced rectal cancer who had } \\
\text { preoperative chemoradiation. }\end{array}$ \\
\hline
\end{tabular}

NLR: Neutrophil:lymphocyte ratio 
A study conducted on patients with stage I-III CRC undergoing curative cancer ${ }^{5}$ found that an elevated NLR was associated with more aggressive clinicopathological factors such as increased size, tumour stage, elevated CEA, low albumin, the presence of disease complications and nonabdominal morbidity.

Pine et al. ${ }^{8}$ found that an elevated NLR was associated with a higher stage, a greater incidence of extramural venous invasion as well as lymph node metastasis. In contrast, a lower NLR was associated with a less aggressive phenotype, for example, they had a pronounced lymphocytic reaction at the invasive margin, associated with a better prognosis.

\section{The NLR and Mismatch Repair Status}

Microsatellites are short, repetitive stretches of DNA interspersed within the whole genome and are susceptible to high rates of mutation. A unique, hypermutable phenotype known as microsatellite instability (MSI-H) results from impaired DNA mismatch repair. Tumours displaying high levels of MSI-H have two molecular types: Lynch syndrome, which occurs from germline mutations of MMR genes, and sporadic colorectal cancers, which arise from epigenetic alterations of the hMLH1 promoter. Tumours displaying loss of MMR protein are known as MMR deficient (dMMR), whereas those with intact MMR protein expression are known as MMR proficient (pMMR), with dMMR tumours having a better prognosis. We know that dMMR tumours have a more favourable local immune response. ${ }^{15}$ Several mechanisms have been suggested to link the systemic inflammatory response and MMR status. Llosa et al. ${ }^{16}$ found that dMMR tumours have a high infiltration with CD8+ T lymphocytes and interferon gamma-producing Thl-cells, leading to an immunologically active anti-tumour microenvironment. Counterbalancing this, MSI tumours had differentially high expression of a number of immune checkpoint proteins e.g. PD1, PDL1, CTLA4, LAG3 and IDO, all of which act as a brake on the immune response to the tumour, making this patient group good candidates for immunotherapy. An alternative hypothesis ${ }^{17}$ is that chronic inflammation can lead to dMMR colorectal cancers though IL6 production, which may change the localisation of human MutS homolog 3 and induce tumours with the dMMR phenotype. Pine et al. ${ }^{8}$ failed to find a correlation between MMR status and NLR, whereas Park et al. ${ }^{18}$ found that dMMR patients had higher neutrophil counts. This inconsistency led He et al. ${ }^{19}$ to explore the relationship between NLR MMR status and survival. In agreement with Park et al. ${ }^{18}$, they found that NLR and C-reactive protein (CRP) were more likely to be raised in dMMR patients with no distant metastases; however, this correlation was stage dependent. With respect to survival data, NLR was not found to be significantly correlated with disease- free and overall survival in dMMR patients, although it did predict survival in pMMR patients. A more recent study ${ }^{20}$ found that among an array of markers of systemic inflammatory response, only a preoperative NLR $>5$ was associated with worse overall survival and greater recurrence in patients with dMMR CRC undergoing surgery. They also found an inversely proportional relationship between NLR and the local inflammatory response in this tumour group. Due to the above-described controversy in the literature on the prognostic effect of NLR in MSI tumours, this area should be a focus of future work.

\section{NLR and the Response to Oncological Treatment in Colorectal Cancer}

A study of patients with advanced CRC receiving palliative oxaliplatin-based chemotherapy found that an elevated NLR was independently associated with poorer overall survival in a multivariate analysis. ${ }^{21} \mathrm{~A}$ high NLR was also associated with a lower objective response and disease control rate compared with the low-NLR group. An analysis of NLR levels conducted in patients enrolled into a multicentre phase III TRIBE trial ${ }^{22}$, which randomised unresectable metastatic CRC patients to receive the triplet FOLFOXIRI plus bevacizumab or doublet FOLFIRI plus bevacizumab, found that patients with an elevated NLR $(>3)$ had significantly shorter progressionfree survival $(\mathrm{HR}=1.27,95 \% \mathrm{CI}=1.05-1.55, \mathrm{p}=0.017)$. They also reported a better objective response rate (65\% vs 53\% $\mathrm{p}=0.006$ ), progression-free and overall survival in the triplet plus bevacizumab group. These data not only support the choice of FOLFOXIRI plus bevacizumab as a preferable firstline treatment for this patient group but also suggest that NLR measurement may be a useful tool for better patient selection for those who would derive more benefit from this more intense chemotherapy regimen.

Kishi et al. ${ }^{23}$ demonstrated that the NLR can be normalised by chemotherapy in 17 out of 25 patients with metastatic colorectal cancer, which also has an impact on survival, suggesting that this biomarker may be useful for predicting the response to chemotherapy. Another retrospective multicentre study ${ }^{24}$ was concordant with the above finding that chemotherapy can normalise the NLR in metastatic CRC patients and consequently achieve a longer time to event for these patients when compared with the patient group whose NLR did not normalise following treatment. In a study of 349 patients with advanced colorectal cancer, Chua et al. ${ }^{25}$ found that normalisation of the NLR following a single cycle of chemotherapy resulted in improved progressionfree survival, leading to the idea that manipulation of the systemic inflammatory response can be of clinical benefit. This observation was supported by Turnbull et al. ${ }^{26}$, who 
found that depressed immune responses in patients with a high baseline NLR could be reversed after 6 weeks of first-line chemotherapy in patients with advanced colorectal cancer, with increased expression of PD-1 on natural killer cells as well as B cells and monocytes, suggesting the identification of this patient group as candidates for immunotherapy.

If a lymphocyte count has not been undertaken, then the derived NLR can be calculated from the following equation: $\mathrm{dNLR}=$ Absolute neutrophil count/(white blood cell countabsolute neutrophil count)

Wood et al. ${ }^{27}$ found that a dNLR $<2.2$ was associated with better overall survival compared with a dNLR $>/=2.2$ in patients receiving oxaliplatin-based chemotherapy in patients with metastatic CRC with RAS and BRAF mutations. The wider literature suggests that the association of high NLR with worse survival is more pronounced in patients with metastatic disease, probably reflecting a greater tumour burden and a more significant chronic inflammatory process. In agreement with a previous study ${ }^{28}$, the correlation between NLR and survival is independent of the mutation group (with the mutations studied being KRAS, NRAS, BRAF, PIK3CA, PTEN loss and CpG Island Methylator Phenotype testing).

Grenader et al. ${ }^{29}$ examined whether the dNLR could predict the effect of intermittent vs continuous chemotherapy in patients with advanced colorectal cancer. They found a strong association between dNLR and overall survival but concluded that it does not add to the prognostic value of the platelet count in selecting patients that would benefit from continuous vs intermittent therapy and therefore cannot be used to select patients for chemotherapy-free breaks. These findings add to the conclusions of the COIN trial ${ }^{30}$, which had previously reported that patients with normal baseline platelet counts would be candidates for intermittent chemotherapy without a survival cost, whereas those with thrombocytosis (platelet count $>400,000$ ) would have better outcomes without a treatment break. The above suggests that the platelet count is a better predictor than dNLR in this regard.

Extrapolating to other oncological treatments, this time with reference to radiotherapy, a raised pre-treatment NLR was associated with significantly worse overall survival in patients with solid tumours with a pooled hazard ratio of 1.90 (95\% CI=1.66-2.17, $\mathrm{p}<0.001){ }^{31}$ This suggests that this biomarker may be useful for risk stratification for patient selection for more aggressive radiotherapy.

With respect to patients with locally advanced rectal cancer, an elevated baseline NLR was noted to predict poorer overall survival but failed to predict the response to treatment following neoadjuvant chemoradiation. ${ }^{32}$ Hodek et al. ${ }^{33}$ evaluated a large group of patients with locally advanced rectal adenocarcinoma who were exposed to neoadjuvant chemoradiation. They found that a NLR range between 2.2 and 2.8 produced a significantly better overall survival and response to treatment; however, the NLR did not have a significant influence on pathologic complete remission. This pattern of observation was replicated by Carruther et al. ${ }^{34}$, who observed that an elevated NLR was a useful prognostic marker in patients treated with chemoradiation. It had predictive power for overall survival, time to local recurrence and disease-free survival.

Placing the above findings into the clinical context, we know that a tumour-free circumferential resection margin (CRM) is a key determinant of cancer outcome following rectal cancer surgery ${ }^{35}$ Preoperative MRI staging is used to select patients for neoadjuvant chemoradiotherapy once it is established that a clear CRM is unlikely to be achieved with initial surgery. The above findings suggest that apart from radiology, the NLR may be an inexpensive, easily accessible biomarker that may provide further prognostic information regarding outcomes of preoperative chemoradiotherapy.

\section{NLR and Postoperative Complications in Colorectal Cancer}

Josse et al. ${ }^{36}$ found that a NLR value of 2.3-5 was associated with the incidence of perioperative complications, of which wound infection was the most common (12\%). The association between an elevated NLR and postoperative infectious complications was corroborated by Kubo et $\mathrm{al}^{4}{ }^{4}$ Anastomotic dehiscence is a major postoperative complication of resectional surgery with high morbidity and mortality rates. A case control study ${ }^{37}$ found that both CRP and NLR were significant predictors of anastomotic dehiscence. However, the granularity that this study provided was that NLR was not as effective as CRP in predicting anastomotic dehiscence, as it had a smaller area under the curve in receiver operating characteristic analysis. Paliogiannis et al. ${ }^{38}$ found that CRP had a high negative predictive value on postoperative day 4 in identifying patients who were unlikely to develop anastomotic leak and would be suitable for discharge. This study also found that the NLR value on postoperative day 4 was correlated with the incidence of anastomotic dehiscence as well as mortality and morbidity from this complication. However, in agreement with Walker et al. ${ }^{37}$, this study also found that the accuracy of NLR based on receiver operating curve analyses had a poorer outcome, suggesting the inferiority of this biomarker in predicting anastomotic leakage compared with CRP. 


\section{NLR as a Component of the Wider Systemic Inflammatory Response}

The exact understanding of what drives a high NLR remains to be elucidated. However, Motomura et al. ${ }^{39}$ have demonstrated a link between the presence of tumourassociated macrophages (derived from splenic monocytes) and IL17-producing T-cells (in both the peritumoral region and the peripheral blood) and a high NLR. The mechanistic explanation behind interleukin (IL) 17 and a high NLR may be that IL17 plays a significant role in neutrophil chemotaxis through the release of CCL2 and CXC chemokines. The authors also suggest an interaction between IL17-producing T-cells and tumour-associated macrophages in the production of the same family of chemokines that attract neutrophils.

Considering how NLR affects tumour immunology, an unpublished study at our institution has found a differential cytokine profile in CRC patients with NLR $<5$ compared with those with a NLR $>5$. Seven cytokines were found to be preferentially upregulated in the low-NLR group. These are IL-1beta, IL2, IL7, IL13, bFGF, interferon gamma and MIP1 alpha. The cocktail of cytokine production in the lowNLR group is thought to skew the immune response to an anti-tumour Thl phenotype in contrast to the pro-tumour environment of the Th2 type immune response in the NLR $>5$ group. In a separate cohort of patients with metastatic colorectal cancer, Chen et al. ${ }^{28}$ found that a high NLR was associated with increased expression of IL-6, IL-8, IL-2R $\alpha$, hepatocyte growth factor, granulocyte-macrophage colonystimulating factor and vascular epidermal growth factor. These functional drivers of an active systemic inflammatory response are associated with angiogenesis, inflammation and tumour growth promotion and found to be specifically linked to the NLR.

\section{The NLR and the Microbiome}

Apart from using the systemic inflammatory response in isolation to predict prognosis in colorectal cancer, there is the suggestion that NLR be used in conjunction with other prognostic parameters of CRC such as the gut bacterial landscape (the gut microbiome).

A previous study ${ }^{40}$ observed that a more diverse gut microbial landscape, which is associated with a beneficial outcome in several conditions, is associated with a lower NLR, thus lending itself to the idea of manipulating the microbiome to alter the systemic immune response to cancer.

\section{Mechanistic Explanations for the Prognostic Value of NLR in Colorectal Cancer}

Tumour-related angiogenesis through vascular endothelial growth factor (VEGF) production has been suggested to be a mechanism through which neutrophils have a pro-tumour effect. Neutrophils can activate cytokines such as IL16, and this is thought to promote cell adhesiveness, invasion and migration. ${ }^{41}$ Lymphocytopenia may signify depression of innate cellular immunity with a decrease in T4 helper lymphocytes and increase in T8 suppressor lymphocytes. This overall balance is tipped towards a pro-neoplastic process when the NLR is raised. ${ }^{2}$

The link between NLR and the response to radiotherapy in solid cancers such as CRC may be hypoxia. With neoplastic progression, the supply of oxygen and nutrients does not match the demand, leading to necrosis and subsequent release of inflammatory mediators that recruit inflammatory cells such as neutrophils. This pro-tumour effect of hypoxia may explain the prognostic role of high NLR in predicting the response to radiotherapy.

\section{A Brief Summary of other Peripheral Serum Inflammatory Biomarkers in Colorectal Cancer ${ }^{42}$ \\ C-reactive Protein Level (CRP)}

This is an acute-phase protein produced by the liver that plays a role in the systemic inflammatory response. Multiple studies ${ }^{43,44,45}$ have found that elevated CRP is correlated with recurrence after surgery for colorectal cancer.

\section{The Glasgow Prognostic Score (GPS)}

The GPS calculated from serum CRP and albumin is widely thought to reflect the systemic inflammatory response to cancer. In a cohort of 1,590 patients with primary colorectal adenocarcinoma ${ }^{46}$, the authors found a predictive effect of GPS on long-term survival in multivariate analysis.

\section{Platelet-to-lymphocyte Ratio (PLR)}

Platelet aggregation and the release of platelet-derived proangiogenic mediators into the vasculature of the tumour micro-environment through degranulation is suggested to influence tumour growth. The findings from a metanalysis ${ }^{47}$ indicate that a high PLR can be used as a predictor of overall survival and clinicopathological parameters such as tumour differentiation and depth of infiltration in patients with CRC, but not disease-free survival.

\section{Carcinoembryonic Antigen (CEA)}

This is an easily accessible peripheral blood marker whose postoperative level is routinely used as tumour marker for prognostication in colorectal cancer. In rectal cancer patients treated with neoadjuvant radiotherapy and chemotherapy, Toiyama et al. ${ }^{45}$ found that elevated CEA was a predictor of poor overall survival. Another study ${ }^{48}$ found that the blood CEA level was an independent predictive biomarker in patients with colorectal cancer.

\section{Comparing Biomarkers in Colorectal Cancer}

When comparing the superiority of one biomarker over another, Kwon et al. ${ }^{49}$ found that PLR was better than 
NLR as a prognostic marker in CRC $(\mathrm{HR}=1.971, \mathrm{p}=0.021)$. Survival curve analysis showed a consistent pattern of progressively poorer survival associated with a larger PLR. Moreover, the PLR was also significantly reported to be related to a positive lymph node ratio, which is known to have prognostic significance in colorectal cancer. Therefore, this study concluded that PLR is the most significant predictor of survival and is related to a more advanced tumour biology, although it is of note that serum CEA also retained significance in this study.

In concordance with the above, a study by Szkandera et al. ${ }^{50}$ supported the role of PLR in predicting time to recurrence in CRC patients undergoing curative resection. Bong et al. ${ }^{51}$ simultaneously examined the prognostic influence of PLR, NLR and CEA in predicting survival in patients with colorectal peritoneal carcinomatosis treated operatively and with chemotherapy. In a multivariate analysis, only PLR retained significance in predicting 5-year overall survival.

However, the above findings were contradicted by Choi et al. ${ }^{52}$ Only a limited number of studies have evaluated both the NLR and PLR in the same population of patients in colorectal cancer. The study found that a high NLR was a negative independent prognostic factor in CRC and predicted a worse recurrence-free and overall survival. Interestingly, this study failed to find a significant association between PLR and survival, although it is of note that Kwon et al. ${ }^{49}$ used a different threshold for high PLR than this study. The findings of Choi et al..$^{52}$ contradict those of a metaanalysis ${ }^{53}$ which found that PLR was a negative predictor of cancer survival ( $\mathrm{HR}=1.60,95 \% \mathrm{CI}=1.35-1.90)$, although it is of note that this study included a heterogenous patient population with cancers of different parts of the GI tract and who were exposed to a variety of oncological treatments. In agreement with Choi et al. ${ }^{52}$, Zhan et al..$^{54}$ found no significant correlations between PLR and clinicopathological characteristics or survival outcomes.

The differential prognostic influence of PLR on CRC is suggested to be due to a variety of factors. Apart from a lack of consensus regarding the optimal cut-off value for PLR, the heterogeneity in tumour specificity and underlying genetic and biological differences between the variety of patient populations used are cited as root causes of these differences, making a fair comparison between studies difficult.

Another study ${ }^{55}$ compared NLR and CEA as prognostic biomarkers in colorectal cancer. They found that an NLR $<5$ was correlated with a better 5-year overall and disease-free survival. A NLR $>5$ was also associated with more aggressive tumour biology (poorer tumour differentiation and larger tumour size). This study also found that there was a direct correlation between NLR and CEA levels. Pooled results of this meta-analysis found that a NLR $>5$ was correlated with a CEA $>5$. Subsequently, it was identified that a CEA $<5$ was correlated with a better complete pathological response (downstaging and complete regression) after receiving oncological therapy. Overall, this study concluded that NLR and CEA were both independent prognostic factors in CRC and directly correlated with each other. A retrospective study ${ }^{56}$ found that in a population of patients with colorectal cancer, that there was no overall correlation between the CEA and NLR, although they retain individual prognostic significance. On the other hand, Kim et al. ${ }^{57}$ argue for the combined use of both CEA and NLR as prognostic markers for outcomes in CRC patients with liver metastases. Zhan et al. ${ }^{54}$ also advocate for the combined used of CEA and NLR for prognostic assessment of CRC patients as a superior biomarker to the independent use of these prognostic markers alone.

Maeda et $\mathrm{al}^{42}$ investigated whether combining the GPS and NLR with clinicopathological factors such as performance status and the extent of distant metastasis was useful. They found that the median survival time was significantly shorter at only 5 months in the high-risk group (consisting of patients with three or four prognostic factors) vs 21.5 months in the intermediate risk group (consisting of patients with one or two prognostic factors) and 37 months in the low-risk group (consisting of patients without any prognostic factors). They suggest that this may be a simple risk classification tool for optimising treatments for patients with advanced colorectal cancer.

\section{The Role of NLR for All Cancers}

A meta-analysis investigating the prognostic effect of NLR on a range of solid tumours found that it was consistently predictive of survival among a variety of cancers at various stages $^{58}$. There was a differential role of NLR in survival in metastatic vs non-metastatic disease, which may also reflect differences in the underlying pathophysiology of the tumour burden or chronicity of the inflammatory process. There was a consistent effect of the NLR on cancer-specific survival, progression-free survival and disease-free survival across both the primary site of malignancy and the cancer stage.

\section{The Utility of the Neutrophil:Lymphocyte Ratio in Entities Outside of Cancer}

Epidemiological studies have demonstrated that chronic low-grade inflammation, measured by the NLR, is linked to a broad range of risk factors for cardiovascular disease such as diabetes mellitus, hypertension, metabolic syndrome, obesity and hyperlipidaemia. ${ }^{59}$ The NLR has also been noted to be of prognostic significance in respiratory conditions such as COPD (in acute exacerbations, as a marker of 
functional status and mortality) ${ }^{60}$, pulmonary embolism (in predicting short- and long-term mortality $)^{61}$ and COVID-19 (predicting the likelihood of acute respiratory distress syndrome and the requirement for ventilation). ${ }^{60,61,62}$ The NLR also has a role to play in neurological conditions, particularly in acute cerebral haemorrhage. ${ }^{63}$ The above evidence suggests that NLR may be a biomarker that can predict outcomes in both neoplastic and non-neoplastic conditions, where the systemic immune response plays a role in the pathophysiology of the disease.

\section{Conclusions, Controversies and Future Ideas}

Studies have identified that NLR has a prognostic effect on multiple aspects of the disease course of those with colorectal cancer, both primary and metastatic. The time point of measurement of the NLR and the cut-off value of the NLR for classification of high and low groups was inconsistent between studies. Moreover, there is a differential effect of the NLR on colon vs rectal tumours. It has been suggested that the effect of NLR is more difficult to assess in rectal cancer patients due to the presence of confounding factors such as neoadjuvant or adjuvant radiotherapy, which makes survival analysis more complex. The pathophysiology of rectal cancers may also be different. For example, there is an anatomical difference in lymphatic drainage between colon and rectal cancer. More advanced lymphatic spread in rectal cancer may make curative surgery more challenging. These differences may explain the difference in the effect of elevated NLR in colon and rectal cancers.

It is of interest that tumour mutation status such as dMMR and pMMR may have a link with NLR, although its association with survival in this patient group is controversial.

Moreover, there is debate in the literature regarding the single best peripheral blood biomarker to use in colorectal cancer. There are studies arguing for the use of other biomarkers such as CRP over the NLR, particularly in cases of anastomotic leaks; however, there is a growing consensus for the use of combined use of biomarkers such as NLR, CEA, PLR and GPS.

The idea is that by predicting the poor outcome of patients with CRC, using the NLR, it may be possible to tailor their treatment to improve their outcomes. Some have suggested the use of COX 2 inhibitors, which have an inhibitory effect on VEGF. ${ }^{23}$ Other suggestions include the use of preoperative granulocyte-macrophage colony-stimulating factor, which may increase the population of dendritic cells in the liver and support their interaction with CD8+ T-lymphocytes, thus having an anti-tumour effect. Another avenue to explore for CRC patients with liver metastases is the use of cancer vaccines to boost the lymphocytic response to tumours.
Future plans may involve harnessing the role of the systemic inflammatory response with other known prognostic factors of colorectal cancer, such as the gut microbiome. The clinical utility of the use of NLR would be to risk stratify patients who undergo curative surgery or oncological treatment such as chemo and radiotherapy. The normalisation of the NLR could be used as a predictive marker of the response to therapy. Moreover, if the consistency of the prognostic effect of NLR in CRC is established, this might lend itself to the idea of manipulating the NLR though the intravenous use of cytokines or interventions that change the gut microbial diversity and composition to alter the prognosis of CRC patients. We know that the gut microbiota can be influenced by oncological treatments such as radiotherapy, stem cell transplantation and chemotherapy. It would therefore be of interest to investigate the link between the microbiome, the NLR and the above oncological treatments in the context of CRC outcomes and response to treatment. This could yield insights into whether the iatrogenic modulation of these key prognostic factors of CRC could change outcomes.

Peer-review: Internally peer reviewed.

\section{Authorship Contributions}

Literature Search: D.B., P.Q., Writing: D.B., P.Q.

Conflict of Interest: No conflict of interest was declared by the authors.

Financial Disclosure: The authors declared that this study received no financial support.

\section{References}

1. Heng Wan YW, Fang S, Chen Y, Zhang W, Xia F, Wang N, Yingli L. Associations between the neutrophil-to-lymphocyte ratio and diabetic complications in adults with diabetes: a cross-sectional study. J Diabetes Res. doi: doi.org/10.1155/2020/6219545

2. Walsh SR, Cook EJ, Goulder F, Justin TA, Keeling NJ. Neutrophillymphocyte ratio as a prognostic factor in colorectal cancer. J Surg Oncol 2005;91:181-184

3. Li H, Zhao Y, Zheng F. Prognostic significance of elevated preoperative neutrophil-to-lymphocyte ratio for patients with colorectal cancer undergoing curative surgery: A meta-analysis. Medicine (Baltimore) 2019;98:e14126.

4. Kubo T, Ono S, Ueno H, Shinto E, Yamamoto J, Hase K. Impact of the perioperative neutrophil-to-lymphocyte ratio on the long-term survival following an elective resection of colorectal carcinoma. International J Colorectal Dis 2014;29:1091-1099.

5. Chiang SF, Hung HY, Tang R, Changchien CR, Chen JS, You YT, Chiang JM, Lin JR. Can neutrophil-to-lymphocyte ratio predict the survival of colorectal cancer patients who have received curative surgery electively? Int J Colorectal Dis 2012;27:1347-1357.

6. Shin JS, Suh KW, Oh SY. Preoperative neutrophil to lymphocyte ratio predicts survival in patients with T1-2N0 colorectal cancer. J Surg Oncol 2015;112:654-657.

7. Hung HY, Chen js, Yeh cy, Changchien CR, Tang R, Hsieh PS, Tasi WS, You JF, You YT, Fan CW, Wang JY, Chiang JM. Effect of preoperative 
neutrophil-lymphocyte ratio on the surgical outcomes of stage II colon cancer patients who do not receive adjuvant chemotherapy. International J Colorectal Dis 2011;26:1059-1065.

8. Pine JK, Morris E, Hutchins GG, West NP, Jayne DG, Quirke P, Prasad KR. Systemic neutrophil-to-lymphocyte ratio in colorectal cancer: the relationship to patient survival, tumour biology and local lymphocytic response to tumour. Br J Cancer 2015;113:204-211.

9. Haram A, Boland MR, Kelly ME, Bolger JC, Waldron RM, Kerin MJ. The prognostic value of neutrophil-to-lymphocyte ratio in colorectal cancer: A systematic review. J Surg Oncol 2017;115:470-479.

10. Tang, H, Li B, Zhang A, Lu W, Xiang C, Dong J. Prognostic significance of neutrophil-to-lymphocyte ratio in colorectal liver metastasis: a systematic review and meta-analysis. PLoS One 2016;11:e0159447.

11. Halazun KJ, Aldoori A, Malik HZ, Al-Mukhtar A, Prasad KR, Toogood GJ, Lodge JPA. Elevated preoperative neutrophil to lymphocyte ratio predicts survival following hepatic resection for colorectal liver metastases. Eur J Surg Oncol 2008;34:55-60.

12. Neal CP, Mann CD, Garcea G, Briggs CD, Dennison AR, Berry DP. Preoperative systemic inflammation and infectious complications after resection of colorectal liver metastases. Arch Surg 2011;146:471-478.

13. Passardi A, Scarpi E, Cavanna L, Dall'Agata M, Tassinari D, Leo S, Bernardini I, Gelsomino F, Tamberi S, Brandes AA, Tenti E, Vespignani R, Frassineti GL, Amadori D, De Giorgi U. Inflammatory indexes as predictors of prognosis and bevacizumab efficacy in patients with metastatic colorectal cancer. Oncotarget 2016;7:33210-33219.

14. Mallappa S, Sinha A, Gupta S, Chadwick SJD. Preoperative neutrophil to lymphocyte ratio $>5$ is a prognostic factor for recurrent colorectal cancer. Colorectal Dis 2013;15:323-328.

15. Ward R, Meagher A, Tomlinson I, O'Connor T, Norrie M, Wu R, Hawkins N. Microsatellite instability and the clinicopathological features of sporadic colorectal cancer. Gut 2001;48:821-829.

16. Llosa NJ, Cruise M, Tam A, Wicks EC, Hechenbleikner EM, Taube JM, Blosser RL, Fan H, Wang H, Luber BS, Zhang M, Papadopoulos N Kinzler KW, Vogelstein B, Sears CL, Anders RA, Pardoll DM, Housseau F. The vigorous immune microenvironment of microsatellite instable colon cancer is balanced by multiple counter-inhibitory checkpoints. Cancer Discov 2015;5:43-51.

17. Tseng-Rogenski SS, Hamaya Y, Choi DY, Carethers JM. Interleukin 6 alters localization of hMSH3, leading to DNA mismatch repair defects in colorectal cancer cells. Gastroenterology 2015;148:579-589.

18. Park JH, Powell AG, Roxburgh CSD, Horgan PG,McMillan DC, Edwards J. Mismatch repair status in patients with primary operable colorectal cancer: associations with the local and systemic tumour environment. Br J Cancer 2016;114:562-570.

19. He WZ, Hu WM, Kong PF, Yang L, Yang YZ, Xie QK, Jiang C, Yin CX, Qiu HJ, Zhang B, ZhangHZ, Xia LP. Systemic neutrophil lymphocyte ratio and mismatch repair status in colorectal cancer patients: correlation and prognostic value. J Cancer 2018;9:3093-3100.

20. Climent M, Ryan EJ, Stakelum A, Khaw YL, Creavin B, Lloyd A, Alhassan D, Mohan HM, Kennelly R, Sheahan K, Winter DC. Systemic inflammatory response predicts oncological outcomes in patients undergoing elective surgery for mismatch repair-deficient colorectal cancer. Int J Colorectal Dis 2019;34:1069-1078.

21. Kaneko M, Nozawa H, Sasaki K, Hongo K, Hiyoshi M, Tada N, Murono K, Nirei K, Kawai K, Sunami E, Tsuno NH, Kitayama J. Elevated Neutrophil to Lymphocyte Ratio Predicts Poor Prognosis in Advanced Colorectal Cancer Patients Receiving Oxaliplatin-Based Chemotherapy. Oncology 2012;82:261-268

22. Dell'Aquila E, Cremolini C, Zeppola T, Lonardi S, Bergamo F, Masi G, Stellato M, Marmorino F, Schirripa M, Urbano F, Ronzoni M, Tomasello G, Zaniboni A, Racca P, Buonadonna A, Allegrini G, Fea E, Di Donato S, Chiara S, Tonini G, Tomcikova D, Boni L, Falcone A, Santini D. Prognostic and predictive role of neutrophil/lymphocytes ratio in metastatic colorectal cancer: a retrospective analysis of the TRIBE study by GONO. Ann Oncol 2018;29:924-930

23. Kishi Y, Kopetz S, Shin Chun Y, Palavecino M, Abdalla EK, Vauthey JN. Blood neutrophil-to-lymphocyte ratio predicts survival in patients with colorectal liver metastases treated with systemic chemotherapy. Ann Surg Oncol 2009;16:614-622.

24. Botta C, et al. 1439 POSTER Treatment-related Changes in Systemic Inflammatory Status, Measured by Neutrophil-to-lymphocyte Ratio, is Predictive of Outcome in Metastatic Colorectal Cancer Patients. Eur J Cancer 2011;47:S181.

25. Chua W, Charles KA, Baracos VE, Clarke SJ. Neutrophil/lymphocyte ratio predicts chemotherapy outcomes in patients with advanced colorectal cancer. Br J Cancer 2011;104:1288-1295.

26. Turnbull SJ, West E, Scott K, Tidswell E, Melcher A, Seymour MT, Ralph C, Seligmann CF. Chemotherapy to reverse diminished immune responses (IRs) associated with a raised neutrophil lymphocyte ratio (NLR) in patients with advanced colorectal cancer (aCRC). J Clin Oncol 2018;36(15_suppl):e15635-e15635.

27. Wood G. Grenader T, Nash S, Adams R, Kaplan R, Fisher D, Maughan $\mathrm{T}$, Bridgewater J. Derived neutrophil to lymphocyte ratio as a prognostic factor in patients with advanced colorectal cancer according to RAS and BRAF status: a post-hoc analysis of the MRC COIN study. Anticancer Drugs 2017;28:546-550.

28. Chen ZY, Raghav K, Lieu CH, Jiang ZQ, Eng C, Vauthey JN, Chang GJ, Qiao W, Morris J, Hong D, Hoff P, Tran H, Menter DG, Heymach J, Overman M, Kopetz S. Cytokine profile and prognostic significance of high neutrophillymphocyte ratio in colorectal cancer. Br J Cancer 2015;112:1088-1097.

29. Grenader T, Nash S, Adams R, Kaplan R, Fisher D, Maughan T, Bridgewater J. Derived neutrophil lymphocyte ratio is predictive of survival from intermittent therapy in advanced colorectal cancer: a post hoc analysis of the MRC COIN study. Br J Cancer 2016;114:612-615.

30. Adams RA, Meade AM, Seymour MT, Wilson RH, Madi A, Fisher D, Kenny SL, Kay E, Hodgkinson E, Pope M, Rogers P, Wasan H, Falk S, Gollins S, Hickish T, Bessell EM, Propper D, Kennedy MJ, Kaplan R, Maughan TS, FRCR on behalf of the MRC COIN Trial Investigators. Intermittent versus continuous oxaliplatin and fluoropyrimidine combination chemotherapy for first-line treatment of advanced colorectal cancer: results of the randomised phase 3 MRC COIN trial. Lancet Oncol 2011;12:642-653.

31. Choi N, Kim JH, Chie EK, Gim J, Kang HC. A meta-analysis of the impact of neutrophil-to-lymphocyte ratio on treatment outcomes after radiotherapy for solid tumors. Medicine 2019;98:e15369.

32. Shen L, Zhang, H Liang L, Li G, Fan M, Wu Y, Zhu J, Zhang Z. Baseline neutrophil-lymphocyte ratio $(\geq 2.8)$ as a prognostic factor for patients with locally advanced rectal cancer undergoing neoadjuvant chemoradiation. Radiation Oncol 2014:9:295.

33. Hodek M, Sirák I, Ferko A, Örhalmi J, Hovorková E, Nikolov DH, Paluska P, Kopecký J, Petera J, Vošmik M. Neoadjuvant chemoradiotherapy of rectal carcinoma: Baseline hematologic parameters influencing outcomes. Strahlenther Onkol 2016;192:632-640.

34. Carruther R, Tho LM, Brown J, Kakumanu S, McCartney E, McDonald AC. Systemic inflammatory response is a predictor of outcome in patients undergoing preoperative chemoradiation for locally advanced rectal cancer. Colorectal Dis 2012;14:e701-e707.

35. Birbeck KF, Macklin CP, Tiffin NJ, Parsons W, Dixon MF, Mapstone NP, Abbott CR, Scott N, Finan PJ, Johnston D, Quirke P. Rates of circumferential resection margin involvement vary between surgeons and predict outcomes in rectal cancer surgery. Ann Surg 2002;235:449-457.

36. Josse JM, Cleghorn MC, Ramji KM, Jiang H, Elnahas A, Jackson TD, Okrainec A, Quereshy FA. The neutrophil-to-lymphocyte ratio predicts major perioperative complications in patients undergoing colorectal surgery. Colorectal Dis 2016;18:O236-O242. 
37. Walker PA, Kunjuraman B, Bartolo DCC. Neutrophil-to-lymphocyte ratio predicts anastomotic dehiscence. ANZ J Surg 2018. doi: 10.1111/ ans. 14369

38. Paliogiannis PA, Zinellu A. Zinellu, Predictive values of c-reactive protein and neutrophil to lymphocyte ratio in detecting anastomotic leak in open colorectal surgery. Digest Surg 2018;35:85.

39. Motomura T, Shirabe K, Mano Y, Muto J, Toshima T, Umemoto Y, Fukuhara T, Uchiyama H, Ikegami T, Yoshizumi T, Soejima Y, Maehara Y. Neutrophil-lymphocyte ratio reflects hepatocellular carcinoma recurrence after liver transplantation via inflammatory microenvironment. Journal of Hepatol 2013;8:58-64.

40. Yoon HY, Kim HN, Lee SH, Kim SJ, Chang Y, Ryu S, Shin H, Kim HL, Lee JH. Association between Neutrophil-to-Lymphocyte Ratio and Gut Microbiota in a Large Population: a Retrospective Cross-Sectional Study. Sci Rep 2018;8:16031.

41. Donati K, Sépult C, Rocks N, Blacher S, Gérard C, Noel A, Cataldo D. Neutrophil-Derived Interleukin 16 in Premetastatic Lungs Promotes Breast Tumor Cell Seeding. Cancer Growth Metastasis 2017;10:1179064417738513.

42. Maeda K, Shibutani M, Otani H, Nagahara, H Ikeya T, Iseki Y, Tanaka H, Muguruma K, Hirakawa K. Inflammation-based factors and prognosis in patients with colorectal cancer. World J Gastrointest Oncol 2015;7:111117

43. Shibutani M, Maeda K, Nagahara H, Iseki Y, Ikeya T, Hirakawa K Prognostic significance of the preoperative serum C-reactive protein level in patients with stage IV colorectal cancer. Surg Today 2015;45:315-321.

44. Nozoe T, Mori E, Takahashi, I Ezaki T. Preoperative elevation of serum C-reactive protein as an independent prognostic indicator of colorectal carcinoma. Surgery Today 2008;38:597-602.

45. Toiyama Y, Inoue Y, Saigusa S, Kawamura M, Kawamoto A, Okugawa Y, Hiro J, Tanaka K, Mohri Y, Kusunoki M. C-reactive protein as predictor of recurrence in patients with rectal cancer undergoing chemoradiotherapy followed by surgery. Anticancer Res 2013;33:5065-5074.

46. Lee SC, Huh JW, Lee WY, Yun SH, Kim HC, Cho YB, Park YA, Shin JK. Prognostic value of serum inflammatory markers in colorectal cancer. Int J Colorectal Dis 2020;35:1211-1219.

47. Tan D, Fu Y, Su Q, Wang H. Prognostic role of platelet-lymphocyte ratio in colorectal cancer: A systematic review and meta-analysis. Medicine (Baltimore) 2016:95:e3837

48. Thirunavukarasu P, Sukumar S, Sathaiah M, Mahan M, Pragatheeshwar KD, Pingpank JF, Zeh H, Bartels CJ, Lee KKW, Bartlett DL. C-stage in colon cancer: implications of carcinoembryonic antigen biomarker in staging, prognosis, and management. J Natl Cancer Inst 2011;103:689-697.

49. Kwon HC, Kim SH, Oh SY, Lee S, Lee JH, Choi HJ, Park KJ, Roh MS, Kim SG, Kim HJ, Lee JH. Clinical significance of preoperative neutrophillymphocyte versus platelet-lymphocyte ratio in patients with operable colorectal cancer. Biomarkers 2012;17:216-222.

50. Szkandera J, Pichler M, Absenger G, Stotz M, Arminger F, Weissmueller M, Schaberl-Moser R, Samonigg H, Kornprat P, Stojakovic T, Avian A, Gerger A. The elevated preoperative platelet to lymphocyte ratio predicts decreased time to recurrence in colon cancer patients. Am J Surg 2014;208:210-214.
51. Bong TSH, Tan GHC, Chia C, Soo KC, Teo MCC. Preoperative plateletlymphocyte ratio is an independent prognostic marker and superior to carcinoembryonic antigen in colorectal peritoneal carcinomatosis patients undergoing cytoreductive surgery and hyperthermic intraperitoneal chemotherapy. Int J Clin Oncol 2017;22:511-518.

52. Choi WJ, Yang Y,Gao P, Chen X,Yu D,Xu Y,Zhao J, Wang Z. Preoperative Neutrophil-to-Lymphocyte Ratio is a Better Prognostic Serum Biomarker than Platelet-to-Lymphocyte Ratio in Patients Undergoing Resection for Nonmetastatic Colorectal Cancer. Ann Surg Oncol 2015;22(Suppl 3):S603-S613

53. Zhou X, Du Y, Huang Z, Xu J, Qiu T, Wang J, Wang T, Zhu W, Liu P. Prognostic value of PLR in various cancers: a meta-analysis. PLoS One 2014:9:e101119.

54. Zhan X, Sun X, Hong Y, Wang Y, Ding K. Combined detection of preoperative neutrophil-to-lymphocyte ratio and CEA as an independent prognostic factor in nonmetastatic patients undergoing colorectal cancer resection is superior to NLR or CEA alone. Biomed Res Int 2017;2017:3809464.

55. Tsai PL, Su WJ, Leung WH, Lai CT, Liu CK. Neutrophil-lymphocyte ratio and CEA level as prognostic and predictive factors in colorectal cancer: A systematic review and meta-analysis. J Cancer Res Ther 2016;12:582-589.

56. Sebahattin Celik, Yllmaz ME, Bilgiç E. Analysis of the Relationship between the Levels of Carcinoembryonic Antigen and Lactate Dehydrogenase, and the Neutrophil/Lymphocyte Ratio in Colorectal Cancer. Immunochem Immunopathol 2016;2. doi: 10.4172/2469-9756.1000119

57. Kim H, Jung H, Kwon SH, Bae SH, Kim HC, Baek MJ, Lee MS. Preoperative neutrophil-lymphocyte ratio and CEA is associated with poor prognosis in patients with synchronous colorectal cancer liver metastasis. Ann Surg Treat Res 2019:96:191-200.

58. Templeton AJ, McNamara MG, Šeruga B, Vera-Badillo FE, Aneja PP, Ocaña A, Leibowitz-Amit R, Sonpavde G, Knox J, Tran B, Tannock IF, Amir E. Prognostic role of neutrophil-to-lymphocyte ratio in solid tumors: a systematic review and meta-analysis. J Natl Cancer Inst 2014;106:djul24.

59. Balta S, Celik T, Mikhailidis DP, Ozturk C, Demirkol S, Aparci M, Iyisoy A. The relation between atherosclerosis and the neutrophil-lymphocyte ratio Clin Appl Thromb Hemost 2016;22:405-411.

60. Pascual-González Y, López-Sánchez M, Dorca J, Santos S. Defining the role of neutrophil-to-lymphocyte ratio in COPD: a systematic literature review. Int J Chron Obstruct Pulmon Dis 2018;13:3651-3662.

61. Karataş MB, İpek G, Onuk T, Güngör B, Durmuş G, Çanga Y, Çakıllı Y, Bolca $\mathrm{O}$. Assessment of prognostic value of neutrophil to lymphocyte ratio and platelet to lymphocyte ratio in patients with pulmonary embolism. Acta Cardiol Sin 2016;32:313-320

62. Ma A, Cheng J, Yang J, Dong M, Liao X, Kang Y. Neutrophil-to-lymphocyte ratio as a predictive biomarker for moderate-severe ARDS in severe COVID-19 patients. Crit Care 2020;24:288

63. Lattanzi S, Brigo F, Trinka E, Cagnetti C, Di Napoli M, Silvestrini M Neutrophil-to-Lymphocyte Ratio in Acute Cerebral Hemorrhage: a System Review. Transl Stroke Res 2019;10:137-145. 